\title{
Natural Convection Heat Dissipation Analysis for High Current Switching Modules
}

\author{
Dong Hee Kang ${ }^{\mathrm{a}}$, Hyun Wook Kang, ${ }^{\mathrm{a},}$, Hyun-Taeck Limb, Mansoo Chang ${ }^{\mathrm{b}}$, Jae-Moon Jung ${ }^{\mathrm{c}}$, Chang-Hee Park ${ }^{\mathrm{c}}$ \\ aDepartment of Mechanical Engineering, Chonnam National University, \\ 77 Youngbong-ro, Buk-Gu, Gwangju 61186, Republic of Korea \\ bReliability \& Safety R\&D Center, Korea Automotive Technology Institute, \\ 303 Pungse-ro, Pungse-myeon, Dongnam-gu, Chenan-si, Chungnam 31214, Republic of Korea \\ cYura Tech, 38 Anmosan-gil, Jeonui-myeon, Sejong-si, Republic of Korea
}

*Corresponding Author: kanghw@chonnam.ac.kr

\begin{abstract}
NOx is one of the regulated emissions from automobile. The cold start in diesel engine has problem to NOx exhaust that rapidly increases. It is necessary to prevent cold start in engine. Heating coils in the engine serve to sustain stable combustion circumstance. Switching modules control the heating coils to heat up in short times. High current flowing into heating coil is controlled by switching modules. Heat is also generated on switching modules in the process of controlling to release high current into the heating coil. Heat management is essential to prevent malfunction of switching modules by high temperature. However, switching modules are surrounded by a sealed plastic case that is difficult to cooling. In this research, we analyze the temperature distribution in the sealed case surrounding switching modules depending on the installation direction of case and the existence of porous membrane on the case wall. The results of surface temperature on the switching modules are calculated for convective heat transfer coefficient and expected working life time of device. As a result, the influence of heat convection coefficient by the installation with y-direction is $39 \%$ higher than other conditions.
\end{abstract}

Keywords: finite volume method, heat management, heat transfer, working life time

\section{Introduction}

Recently, issues of regulation on automobile exhaust gas are being considered to improve atmospheric environment all over the world. Euro 6 emission standards regulate NOx emissions from automobile under $0.4 \mathrm{~g} / \mathrm{kWh}$. One of the leading causes of NOx emissions is cold start problem when the engine starts up. NOx emissions are rapidly increased to 2.3 and 4.25 times in cold starting condition of diesel and gasoline vehicles, respectively ${ }^{(1-5)}$.

The preheat temperature in the engine room is sustained through heating coil to prevent the cold starting condition. Heating coils are heated up to $1200{ }^{\circ} \mathrm{C}$ within a few seconds to satisfy the conditions for optimal engine combustion. Heating coils are controlled by high current power switching modules. Switching modules regulate current over $20 \mathrm{~A}$ to maintain a steady state of the heating system. Heat is generated in switching modules in the process of controlling high current. Cooling of switching modules is essential to prevent malfunction of heating coil. However, it is difficult to cooling of switching module, because switching modules are embedded on PCB layer that is surrounded by a plastic cover case. The plastic sealed case is effective to moisture resistance, but vulnerable to heat release. A Fan which is used for the forced convection flow is difficult to apply on the sealed case considering the production costs. Therefore, cooling of switching modules is limited except for natural convection conditions in sealed case.

In this research, we consider to installation direction of sealed case and to insert the porous membrane in case wall for cooling of switching modules ${ }^{(6,7)}$. The temperature results on switching modules and air in the sealed case are obtained through the FVM.

\section{Numerical Modeling}




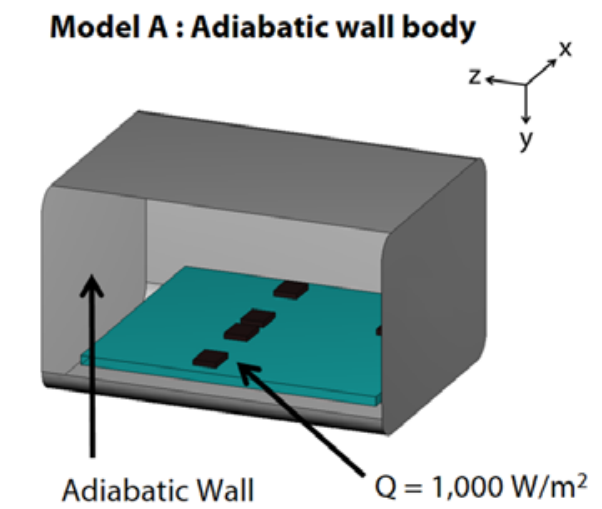

\section{Model B : Adiabatic wall body} with porous structure

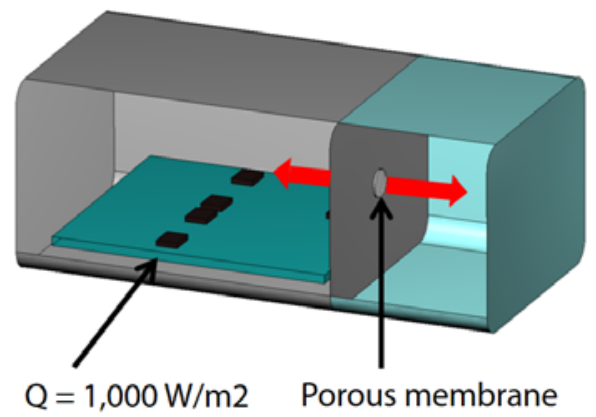

Figure 1. Simplified model for heat convection analysis in adiabatic cover case with porous membrane condition

\subsection{Conditions of numerical analysis model}

In FVM simulation, the switching module embedded PCB is surrounded to $43 \mathrm{~mm} \times 34 \mathrm{~mm} \times 56 \mathrm{~mm}$ adiabatic cover case. As shown in fig.1, switching modules in the FVM simulation model are composed with 5 chips on PCB layer and surrounded by completely enclosed adiabatic cover case as model $\mathrm{A}$. In the model $\mathrm{B}$, switching modules are surrounded by an adiabatic cover case with a $6 \mathrm{~mm}$ diameter and $1 \mathrm{~mm}$ thickness porous membrane on one section of the case wall. The amount of generated heat flux on switching modules are calculated by temperature gradient in the initial 5 seconds from operating condition of the highly accelerated life testing (HALT) results of the switching module. The air temperature in the cover case is set to the natural convection condition and the initial convective heat transfer coefficient is set to $20 \mathrm{~W} / \mathrm{m}^{2} \mathrm{~K}$, (Generally, natural convection coefficient is $5-25 \mathrm{~W} / \mathrm{m}^{2} \mathrm{~K}$ ), and the initial temperature is $300 \mathrm{~K}$. The direction of gravity in each case is considered to $\mathrm{x}, \mathrm{y},+\mathrm{z}$ and $-\mathrm{z}$, in order to analyze effect of the cooling direction of the body case such as table 1 .
Table 1. Simulation condition of heat convection model by the variation of body case shape (model A and B) and gravity force direction $(\mathrm{x}, \mathrm{y}, \mathrm{z},-\mathrm{z})$.

\begin{tabular}{ccc}
\hline Model & Wall & Gravity force \\
index & condition & direction \\
\hline A-(x) & Adiabatic & $+\mathrm{x}$ \\
A-(y) & wall & $+\mathrm{y}$ \\
A-(-z) & $-\mathrm{z}$ \\
A- $(+\mathrm{z})$ & Adiabatic wall with & $+\mathrm{z}$ \\
\hline B-(-z) & porous membrane & $+\mathrm{z}$ \\
\hline B- $(+\mathrm{z})$ &
\end{tabular}
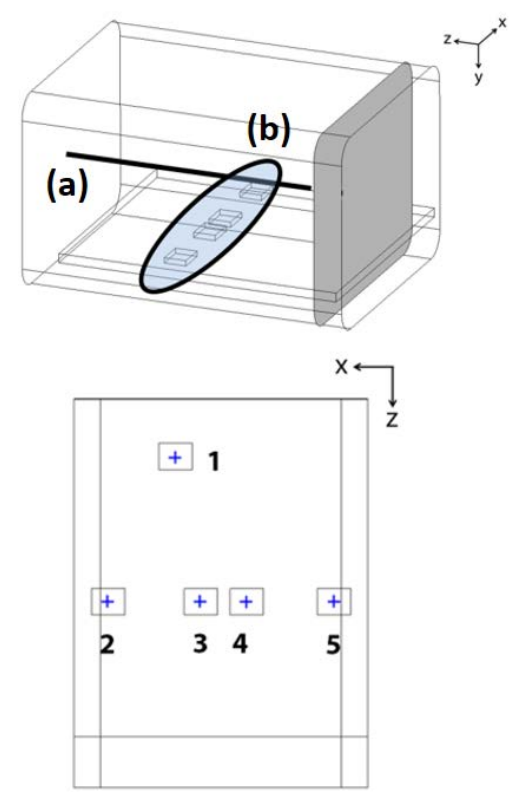

Figure 2. Temperature measurement area from the numerical analysis at (a)center line of the air in cover case and (b) 5 points of switching module surface.

Table 2. Analysis results of the average air temperature and switching module in $600 \mathrm{sec}$.

\begin{tabular}{cccccc}
\hline 600 sec & $\begin{array}{c}\mathrm{q}^{\prime \prime} \\
{\left[\mathrm{W} / \mathrm{m}^{2}\right]}\end{array}$ & $\begin{array}{c}\mathrm{h} \\
{\left[\mathrm{W} / \mathrm{m}^{2} \mathrm{~K}\right]}\end{array}$ & $\begin{array}{c}T_{\text {air }} \\
{[\mathrm{K}]}\end{array}$ & $\begin{array}{c}T_{i c} \\
{[\mathrm{~K}]}\end{array}$ & $\begin{array}{c}\Delta \mathrm{T} \\
{[\mathrm{K}]}\end{array}$ \\
\hline A-(x) & 1000 & 117.3 & 318.6 & 327.1 & 27.1 \\
A-(y) & 1000 & 160.6 & 324.7 & 330.9 & 30.9 \\
A-(-z) & 1000 & 113.5 & 319.3 & 328.1 & 28.1 \\
A-(+z) & 1000 & 115.7 & 319.2 & 327.8 & 27.8 \\
B-(-z) & 1000 & 116.8 & 320.4 & 329.0 & 29.0 \\
B-(+z) & 1000 & 115.3 & 320.1 & 328.8 & 28.8 \\
\hline
\end{tabular}




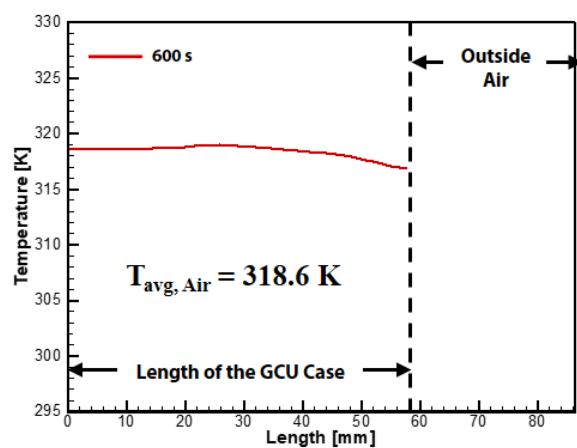

(a) A-(x)

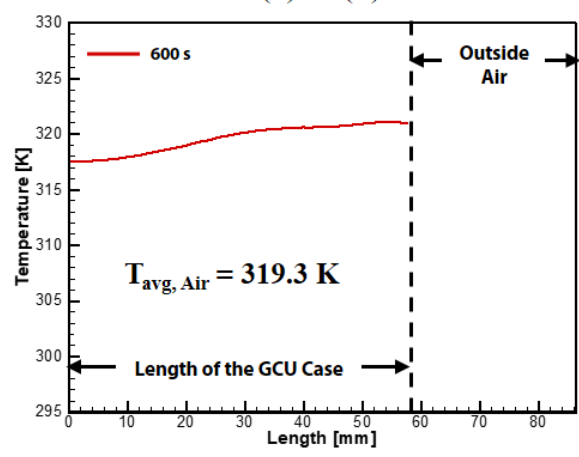

(d) A- $(+\mathrm{z})$

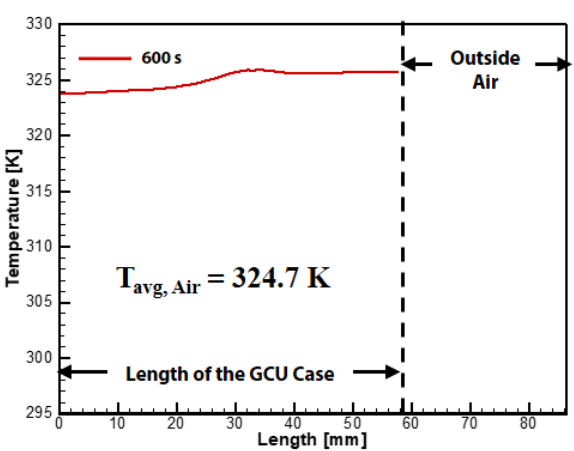

(b) A-(y)

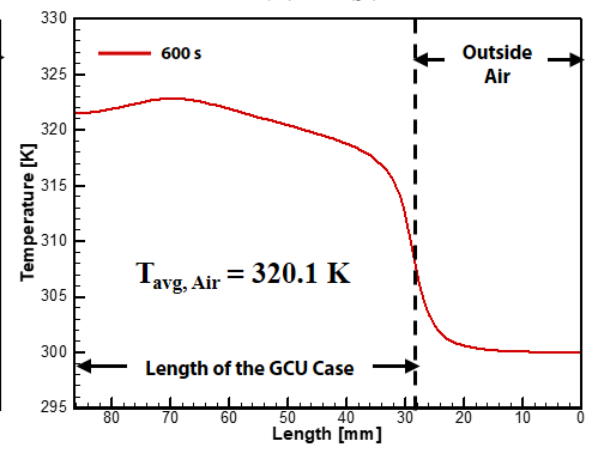

(e) B-(-z)

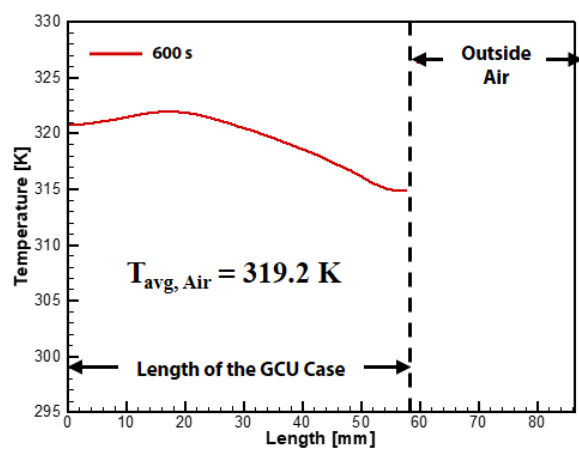

(c) A-(-z)

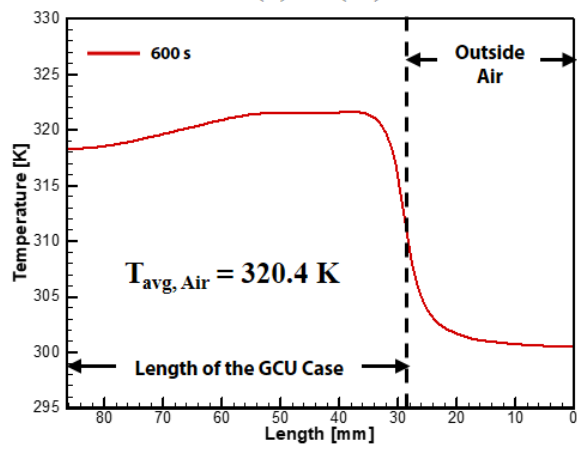

(f) $\mathrm{B}-(+\mathrm{z})$

Figure 3. Temperature variation on centerline of air in sealed case for $600 \mathrm{sec}$

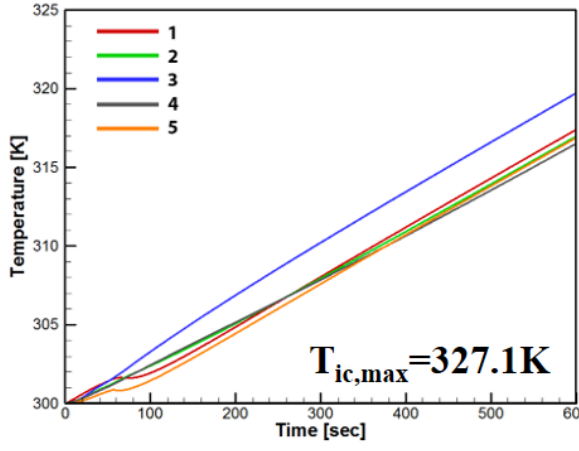

(a) $\mathrm{A}-(\mathrm{x})$

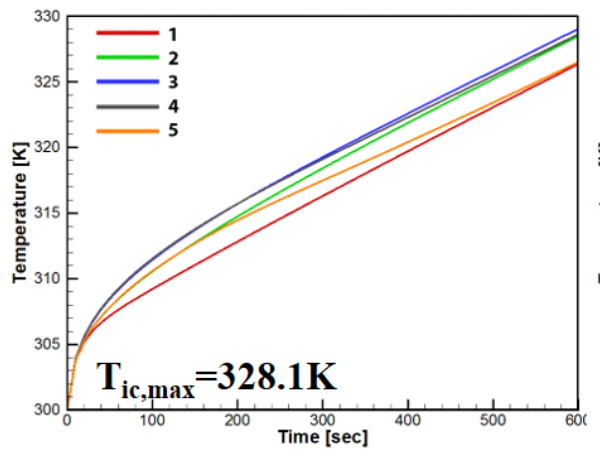

(d) $\mathrm{A}-(+\mathrm{z})$

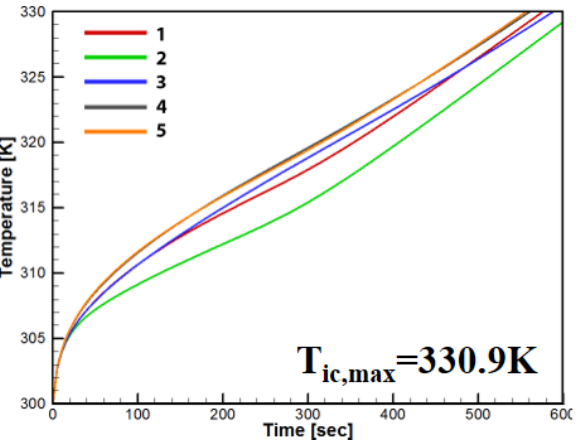

(b) A-(y)

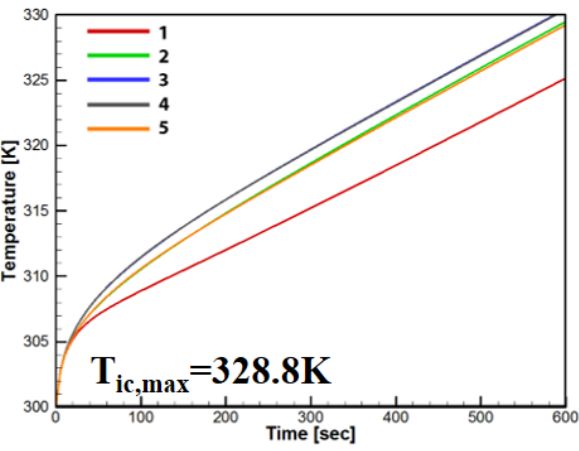

(e) B-(-z)

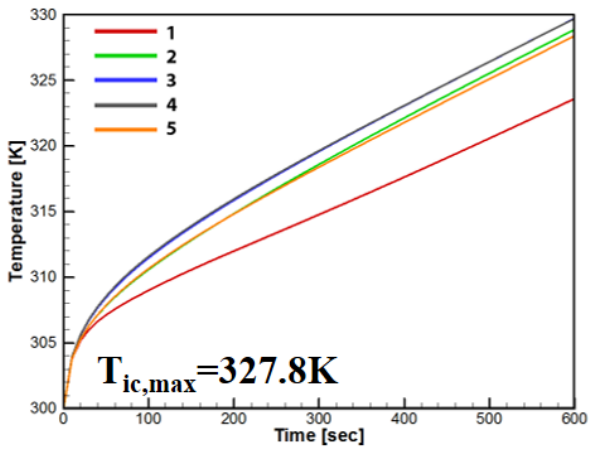

(c) A-(-z)

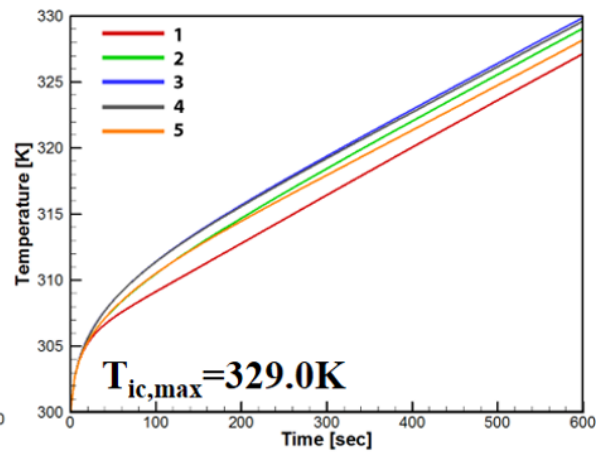

(f) $\mathrm{B}-(+\mathrm{z})$

Figure 4. Temperature variation of each point of the switching module surface 


\subsection{Equations}

The amount of generated heat on the switching module surface is calculated in fitting data of temperature distribution of HALT. Temperature is calculated using lumped capacitance method in eq. (1).

$$
\frac{Q_{i c}}{A}=\rho \cdot c_{p} \cdot \mathrm{t} \cdot \Delta \mathrm{T}
$$

From the calculation results, the heat flux on switching module is $1 \mathrm{~kW} / \mathrm{m}^{2}$. Characteristic of porous membrane on the sealed case wall is calculated by Darcy's law in eq. (2).

$$
Q_{d}=\frac{\kappa A\left(p_{a}-p_{b}\right)}{\mu L}
$$

Permeability $\left(\kappa, \mathrm{m}^{2}\right)$ is a measure of the ability of fluid to flow through the pores of a material. The permeability is calculated from the results of flow rate $\left(\mathrm{Q}_{\mathrm{d}}\right)$ of air through porous membrane, difference of pressure $(\Delta \mathrm{p})$, viscosity of the fluid ( $\mu$ ), film thickness (L), and film area (A). Convective heat transfer coefficient is calculated for the analysis of the convection results using Newton's cooling law in eq. (3).

$$
\mathrm{h}=\frac{Q_{i c}}{A\left(T_{i c}-T_{A i r}\right)}
$$

The temperature difference between the ambient air in sealed case and switching module temperature is obtained by average value of the 1000 points of air and center point of switching modules respectively. The Arrhenius life stress relation is calculated in eq. (4).

$$
\ln L=\ln \alpha+\frac{E_{a}}{k T_{i c}}
$$

Arrhenius model is one of the accelerated life testing methods that calculate based on accelerated failure time model due to temperature effects.

\section{Results and discussion}

The temperature of the switching modules and surrounding air is obtained at each surface and the centerline of cover case for 10 minutes respectively as shown in fig. 2 . In all cases, temperature distribution results show different tendency. Analysis results show high temperature dissipation in the air in A-(y) condition that has positive y direction of gravitational acceleration as shown in table 2. In model A-(- $\mathrm{z}$ ) case, the temperature difference is $7 \mathrm{~K}$ in centerline air temperature as shown in fig. 3. Particularly, in the case of the $\mathrm{z}$ direction of gravitational acceleration, porous membrane assists dissipation of hot air to outside of cover case through the porous membrane as shown in fig. 3e and 3f. The temperature near the porous film shows drastically decreasing to outside temperature, $300 \mathrm{~K}$. On switching module surface, the maximum temperature is $329 \pm 2 \mathrm{~K}$ in all cases that there is no significant effect to cooling effect on switching modules in fig. 4. Overall, average convective heat transfer coefficient is $115 \mathrm{~W} / \mathrm{m}^{2} \mathrm{~K}$. A-(y) condition shows $39 \%$ high coefficients than other coefficients in 600 sec. From the temperature results, the expected life expectancy is calculated to 7,700 and 9,800 hours at the highest and lowest temperature on switching module surfaces respectively. As a result, the warranty life time to using 15 years (60 hours working time per 1 year) can be guaranteed as high as 59.38 $\mathrm{K}$ than ambient temperature.

\section{Conclusions}

In this study, heat dissipation is analyzed to temperature of the high current switching module depending on the installation direction and the existence of porous membrane on the insulated cover case through FVM. Heat dissipation is caused by natural convection heat transfer in the ambient air surrounding the switching module. In heat dissipation simulation, the switching module that is composed of 5 chips on the PCB board with $1000 \mathrm{~W} / \mathrm{m}^{2}$ heat flux in 600 seconds. From the analysis results, the air inside the cover case show uneven temperature distribution due to the heated air rises in the opposite direction of gravity. The temperature near the case wall with porous membrane is rapidly reduced when the heated air reach on the porous membrane. However, the average temperature inside the case and the surface on the switching module is maintained at $319 \pm 1 \mathrm{~K}$ and $329 \pm 2 \mathrm{~K}$ in 600 seconds respectively. Especially, in the y direction gravity acceleration, the average temperature of air is $324 \mathrm{~K}$ that causes the $39 \%$ high convective heat transfer coefficient than other conditions. From the Arrhenius life stress relation, temperature results of the switching module show the expected life time of the switching module over 7,700 hours. As a result, under the temperature conditions in this analysis has no problem to use switching module more than expected life time. And the influence of the installation with $y$ direction is greater than the existence of the porous membrane. In future works, the durability life estimation 
should be considered not only the temperature but also the ambient humidity for estimate accurately the expected working time of devices.

\section{Acknowledgment}

This research is supported by "Reliability Technology Diffusion" through the Ministry of Trade, Industry and Energy (MOTIE) (N0001906, 2016) and "Basic Science Research Program" through the National Research Foundation of Korea (NRF) funded by the Ministry of Science, ICT \& Future Planning (2016R1C1B2012136).

\section{References}

(1) Martin Weilenmann, Jean-Yves Favez, and Robert Alvarez : "Cold-start emissions of modern passenger cars at different low ambient temperatures and their evolution over vehicle legislation categories", Atmospheric Environment, Vol. 43, No. 15, pp. 24192429, 2009

(2) Reyes García-Contreras, Octavio Armas, Carmen Mata, and Octavio Villanueva : "Impact of Gas To Liquid and diesel fuels on the engine cold start”, Fuel, Vol. 203, pp. 298-307, 2017

(3) Pablo Mendoza-Villafuerte, Ricardo Suarez-Bertoa, Barouch Giechaskiel, Francesco Riccobono, Claudia Bulgheroni, Covadonga Astorga, and Adolfo Perujo : "NOx, NH3, N2O and PN real driving emissions from a Euro VI heavy-duty vehicle. Impact of regulatory onroad test conditions on emissions", Science of the Total Environment, Vol. 609, pp. 546-555, 2017

(4) C. L. Myung and S. Park : "Exhaust nanoparticles emissions from internal combustion engines: A review”, International Journal of Automotive Technology, Vol. 13, No. 1, pp. 9-22, 2012

(5) Timothy Johnson : "Vehicular Emissions in Review", SAE International Journal Engines, Vol. 9, No. 2, pp. 1258-1275, 2016

(6) Jin-Huek Hur, Tae-Gu Lee, Sun-Ae Moon, Sang-Jae Lee, Hoseon Yoo, Seung-Jae Moon, Jae-Heon Lee : "Thermal reliability analysis of a BLDC motor in a highspeed axial fan by the accelerated-life test and numerical methods”, Heat and Mass Transfer, Vol. 44, No. 11, pp. 1355-1369, 2008

(7) Ephraim Suhir : "Could electronics reliability be predicted, quantified and assured?” Microelectronics Reliability, Vol. 53, No. 11, pp. 925-936, 2013 